\title{
INTERSEÇÕES NECESSÁRIAS: HISTÓRIA, MUSEOLOGIA E MUSEUS DE CIÊNCIAS E TECNOLOGIA
}

\author{
Maria Esther Alvarez Valente ${ }^{{ }^{*}}$
}

\section{RESUMO:}

Ao acompanhar o movimento do fortalecimento da disciplina da museologia, o presente artigo se inscreve no universo das pesquisas que seguem especialmente a história dos museus, tomando parte na consolidação da museologia, com o foco voltado aos museus de ciências e tecnologia. A intenção é a de apresentar uma reflexão sobre um viés, inspirado na perspectiva da história da ciência, utilizada nesse caso para o conhecimento da criação de museus de ciências e tecnologia, no sentido de discorrer sobre um caminho que pode ser tomado para explorar o tema e que já tem adensado a reflexão em torno dessa categoria de museu.

\section{PALAVRAS-CHAVES:}

Museus de Ciência e Tecnologia. História da ciência. Museologia e produção de conhecimento.

\begin{abstract}
:
Accompanying the movement of strengthening the discipline of museology, this paper falls within the universe of research that specifically follows the history of museums, taking part in the consolidation of the museology, with the focus turned to museums of science and technology. The intention is to present a reflection on a bias, inspired by the history of science perspective. Knowledge used, in this case, to understand the creation of museums of science and technology in order to discuss a way, which can be taken to explore the topic, which already has been density planting reflection on this category of museum.
\end{abstract}

\section{KEY-WORDS:}

Museums of Science and Technology . History of science. Museology and knowledge production 
A produção de conhecimento no museu se dá sobre o conjunto de seus domínios, instituído pelas atividades intelectuais acadêmicas e por suas ações de organização de trabalho, procurando um aprofundamento, seja da compreensão da complexidade das diferentes dimensões da instituição, seja da constituição de um corpo disciplinar de saberes que atendem as especificidades do campo museal. Cumpre sublinhar que, embora as discussões sobre esse campo de saber se tencionem no que diz respeito à separação da instituição museu da área disciplinar da museologia, os dois aspectos estão imbricados em suas origens.

Cabe, ainda, ressaltar que, as funções fundamentais do Museu, incorporadas à instituição desde sua constituição renascentista, guardadas as consequentes atualizações, ao longo do tempo, continuam sendo de pesquisar, preservar e difundir conhecimentos e, são elas em suas diferentes dimensões (social, educacional, comunicacional, econômica, política, cultural etc.), que vêm sendo estudadas por diferentes pontos de vista (histórico, antropológico, sociológico etc.).

Nesse sentido a definição formal de museu, proposta pelo Conselho Internacional de Museus - $\mathrm{ICOM}^{2}$, que tem sido parâmetro para a criação de museus pelo mundo e base dos estudos da área da museologia, é discutida sistematicamente desde 1946. Durante a $21^{\text {a }}$ Conferencia Geral do ICOM em Viena, em 2007, a definição sofreu uma importante atualização e nela o termo 'pesquisa' foi substituído por 'estudo'3. A mudança não visou suprimir essa função do museu, mas visou deslocar a concepção de pesquisa sobre os testemunhos materiais do homem e da sociedade adquiridos, preservados e expostos no museu, para outra concepção a que se refere ao processo de desenvolvimento do conhecimento e, que permite o espírito de compreensão da formação de seu campo de atuação museal, em diferentes setores culturais (BERGERON; DAVALLON, 20I I, p. 527).

A realização de pesquisas acadêmicas sobre a natureza da museologia vem ocorrendo ao longo dos últimos 60 anos, por meio de instituições acadêmicas dedicadas aos estudos de museus (museums studies), principalmente na Europa e nos Estados Unidos. $\mathrm{Na}$ atualidade, entretanto, o museu conquistou uma importância destacada enquanto objeto de estudo. $O$ fato de maior intensidade de pesquisas, ocorridas nas últimas três décadas, tem sido observado em diferentes disciplinas das ciências sociais e humanas que escolhem como objeto de análise a instituição. Tendência refletida nos inúmeros $\operatorname{cursos}^{4}$ de graduação e pós-graduação, de museologia, que foram implantados em diferentes universidades espalhadas no território brasileiro a partir da primeira década deste século. Disposição que já vinha sendo anunciada pelas pesquisas produzidas em diferentes departamentos disciplinares das universidades brasileiras e em outros fóruns independentes.

Ao acompanhar esse movimento, o presente artigo se inscreve no universo dos trabalhos que seguem especialmente a história dos museus na consolidação da área da museologia, com foco voltado aos museus de ciências e tecnologia.

$O$ artigo tem por intenção apresentar uma reflexão sobre uma perspectiva utilizada para o conhecimento da criação de museus de ciências e tecnologia, no sentido de discorrer sobre um caminho que pode ser tomado para explorar

2 Para saber sobre o ICOM consulte: <http://icom.museum/the-organisation/icom-in-brief/>.

3 A definição mais atualizada de Museu é de 2007. Um museu é uma instituição permanente, sem fins lucrativos, a serviço da sociedade e seu desenvolvimento, aberto ao público, que adquire, conserva, estuda, expõe e comunica o património material e imaterial da humanidade e de seu ambiente para fins de estudo, educação e lazer. De acordo com: Bergeron e Davallon (2011).

4 Para saber sobre os Cursos de Museologia em graduação e pós-graduação acesse: <http://www.concursosmuseologia.com.br/p/onde-estudar.html>. 
o tema e que já tem adensado a reflexão em torno dessa categoria de museu. A partir da motivação por esse interesse, o que muda inicialmente é o foco do conhecimento, bastante frequente, de caráter personalista para abordar a história de determinadas instituições.

No que concerne aos tópicos de perspectiva histórica das instituições museológicas, as pesquisas pouco se dedicam a observar seus contextos mais amplos e, com certa constância, estão desconectadas das circunstâncias de criação, indo pouco além de uma descrição interna da instituição. $O$ conhecimento sobre o museu fica, em alguns casos, circunscrito a iniciativas pessoais isoladas. Análises pouco aprofundadas podem reforçar uma percepção do senso comum, que confere ao esforço individual a prerrogativa da responsabilidade pelo empreendimento museológico. Sem dúvida alguma, as personalidades que estiveram à frente dos projetos de museu tem seu lugar registrado, mas estes não estavam sozinhos e lidaram com outros condicionantes e diferentes atores que ora deram sustentação, ora atuaram no sentido oposto de adiamento, ou mesmo de obliteração da iniciativa da criação de um museu.

A proposta desse desvio visa, sobretudo, evitar o risco da idealização de pessoas e disciplinas ou saberes, procurando penetrar de maneira mais consciente e crítica sobre a investigação das relações entre atores e contextos na produção de um conhecimento institucional. Além, das concepções que são construídas para a criação e desenvolvimento dos museus.

\section{Uma linha de interpretação para conhecer o museu de ciência e tecnologia}

A apresentação desta reflexão parte do entendimento que investigar o museu do limite de uma museologia restrita ao interesse particular de suas práticas (preservação, pesquisa das coleções e comunicação) não é suficiente para se conhecer a instituição e para se construir um arcabouço teórico do campo da museololgia. Seus inúmeros aspectos só podem ser desvelados se examinados também por outras perspectivas, face à característica intrínseca da multidisciplinaridade da museologia.

No horizonte da história dos museus de ciências e tecnologia, o museológico tem sua prioridade, mas para pensar sobre essa categoria de museu é importante considerar a história da ciência e as visões críticas relacionadas a seus desdobramentos, como o entendimento público da ciência (public understanding of science); os estudos sociais da ciência; a história social e cultural, a cultura científica e a comunicação social da ciência, entre outros. Sendo assim, é imprescindível a interseção de diferentes disciplinas, além da museologia, para a compreensão da atualidade dessa instituição e de seu campo disciplinar.

A aproximação com outros caminhos de interpretação em uma proposta de pesquisa que tem os museus de ciência e tecnologia como foco vem aprofundar e fortalecer, efetivamente, o conhecimento e entendendimento desses museus.

Com esse propósito, procura-se levantar as condições de produção e incorporação de modelos institucionais de museu que guardam conceitos a partir de representações e significados forjados nesse processo, não só pela museologia, como por outras áreas de conhecimento. Procura-se ainda compreender os meandros desse movimento, relacionando as circunstâncias que viabilizaram a ocorrência do surgimento desses espaços museológicos, com os próprios museus investigados.

Os estudos, de caráter interdisciplinar, com ênfase no eixo de pesquisa da história da museologia devem, nesse caso, privilegiar a abordagem de investigação inserida na área disciplinar da história da ciência. Essa perspectiva reno- 
vadora dos estudos da ciência trouxe, a partir dos anos 1970, um enfoque que vai explorar a História da ciência como parte intrínseca da sociedade. "Não é mais localmente, apenas no espaço dos laboratórios, que o segredo dos saberes (científicos) e de sua validação é buscado, mas nas retomadas das traduções que operam no conjunto do corpo social" (PESTRE, 1996, p. I2).As produções científicas passam a ser tratadas igualmente como todas as outras produções culturais geradas pelos indivíduos. "Tudo que o homem propõe são construções que por sua vez são inseparáveis da cultura mais vasta.Aceitar o intrincado cultural das relações é fundamental para entender como se desenvolvem os homens no fazer da ciência" (PESTRE, 1996, p. 18).

Esse entendimento foi básico para o desenvolvimento de projetos de pesquisa na área dos museus de ciências, entre os quais dois serão citados. $O$ estudo de Handfas (2013) que tratou das relações entre as políticas públicas de ciência e tecnologia, e os museus de ciência, a preservação do patrimônio da ciência e tecnologia brasileira e o campo da museologia. Nessa articulação procurou conhecer os conceitos museológicos adotados durante a trajetória do Museu de Astronomia e Ciências Afins. A pesquisa de Valente (2009) teve como objetivo central compreender o processo que 'pavimentou' o ambiente no qual foram forjados os projetos que impulsionaram o surgimento dos museus de ciências e tecnologia nos anos de 1980 no Brasil e para tal investiu em atores e instituições de ciência e tecnologia fora dos museus.

A análise da questão da proliferação de museus de ciências e tecnologia no Brasil, por exemplo, implica não só na aproximação com uma das possibilidades abertas pela história da ciência como também vem contribuir na ampliação de fontes para as áreas disciplinares envolvidas no estudo. Adicionalmente, vem colaborar com uma melhor compreensão da própria instituição, sugerindo um aperfeiçoamento de sua existência, ponto de vista sublinhado pelo historiador da ciência, Bennett (2005, p. 605). Ele se refere, aqui, às análises críticas sobre museus produzidas pela pesquisadora da mesma área de conhecimento Kohlstedt (2005):

Examinando a riqueza do recente material, ela (Sally G. Kohlstedt) demonstra, ainda mais enfaticamente do que antes, a importância e produtividade do foco atual nas atividades dos museus. A intensidade e precisão desse foco e a sutileza da introspecção resultante podem dar aos museus autônomos em sua própria disciplina, que trabalham com coleções de ciência, uma pausa para reflexão.Visto que decidem sobre suas aquisições, planejam suas exposições, e negociam os temas e conteúdos de exposições especiais com gerentes, designers, conservadores, educadores, contabilistas, profissionais das relações públicas, segurança, peritos, carpinteiros, eletricistas, e todo um número de outros especialistas do museu (KOHLSTEDT, 2005 apud BENNETT, 2005, p. 605).

As referências usadas para explorar o tema da história dos museus de ciência são inspiradas em reflexões de diferentes historiadores da ciência. Entre eles destacam-se os trabalhos realizados por Maria Margaret Lopes, cuja vasta produção tem dedicado inúmeros estudos à temática da história da museologia $^{5}$. A perspectiva está alinhada com a tendência da historiografia das ciências que questiona o status epistemológico superior atribuído à ciência, e por isso abandona a noção da existência de uma única forma de conhecimento e rompe com a prática da excepcionalidade dos personagens e teorias. Consoante com esse plano está também a rejeição à dicotomia entre os aspectos do contexto

5 Ver: Lopes (1988; 199I; 1992; 1996; 1997; 200I; 2002; 2003b; 2004; 2005; 2006a; 2006b; 2009); Lopes e Valente (2009); Lopes e Murriello (2000); Lopes e Murriello (2005); Lopes e Figueirôa (2003). 
e do processo intelectual, na construção do conhecimento. Assume-se, portanto, a interpretação das atividades de cunho científico pelo viés sociocultural, incorporando as dimensões temporal, espacial e social. Essa posição, também, tem sido bem recebida nos estudos sociais da ciência realizados nos países da América Latina, e não somente os provenientes do bloco geográfico das regiões localizadas no hemisfério norte. Baseados nessa percepção serão aqui destacados aspectos importantes para subsidiar o desenvolvimento da análise crítica sobre os museus de ciências e tecnologia.

\section{Aspectos de uma linha de interpretação}

A orientação de reflexão a ser seguida, sobre um material destacado para análise, por exemplo, da história de um museu de ciências (documentos institucionais, de diferentes esferas governamentais, entrevistas, relatórios, manuais, catálogos etc.), considera três elementos básicos no entendimento do movimento da museologia das ciências ${ }^{6}$. São eles a linguagem, o tempo e o contexto de produção do discurso integrado ao aspecto da cognição. Esses elementos, carregados de seus correspondentes limites, combinam-se das mais diversas maneiras e deixam entrever diferentes marcas na constituição do que foi produzido no museu. A compreensão da existência da pluralidade de modos de fazer ciência auxilia o olhar do pesquisador/historiador na detecção de várias direções e concepções de ciência, trazidos pelos sujeitos envolvidos no processo de discussão dos equipamentos museológicos. Uma análise das concepções de ciências, em museus dessa temática, foi recentemente realizada por Aragão (20I3), ao investigar três instituições museológicas, para a autora:

[...] fica evidente que onde há ciência há também concepções de ciência pré-estabelecidas e, sendo assim, em museus e centros de ciência não poderia ser diferente. Nesses espaços, a ciência e suas concepções emergem de diferentes formas e também a possibilidade de haver diferentes concepções interagindo no mesmo ambiente não é pequena. Contudo, devido às suas características específicas, outros fatores devem ainda ser considerados para pensar a forma como a ciência é vista e trabalhada nessas instituições de educação não formal (ARAGÃO, 20।3, p. 36).

Ao contemplar o universo da construção da ciência, marca dessas instituições, sublinha-se sua importância para o desenvolvimento de programas de caráter sociocientifico dos museus. Muitas vezes os instrumentos científicos, assim como a organização dos espaços arquitetônicos de um patrimônio museológico de natureza científica e tecnológica só fazem sentido, vistos em um determinado conjunto e/ou pelas circunstâncias de aquisição dos objetos e construção dos espaços para a produção da ciência. Vistos isoladamente, por exemplo, muito frequentemente, dificultam ou mascaram a compreensão sobre um determinado conhecimento científico.

A partir dessa orientação, a identificação de diferentes atitudes (ausências, inclusões, exclusões, permanências) reconhecidas como representantes do dito e do não dito e que imprimem significados, podem ser mais bem percebidas no processo de construção do movimento museológico. Entretanto, essas atitudes devem ser observadas sem se perder de vista que o observador traz em si outro contexto e outro tempo na produção de suas formas de interpretar e dizer.

Seguindo o proposto pela nova historiografia das ciências, identificam-se pistas que revelam o que não está explícito. Os documentos e falas em torno da

6 Termo usado para caracterizar as atividades e estudos referentes aos museus de ciência e tecnologia. Esta denominação é usada pelo pesquisador da área Schiele e Koster (1998). 
criação de museus aproximam a visualização dos diferentes elementos, divergências, coerências e relações internas e externas ocorrendo, com ênfases e ritmos diversos, abrindo, ao mesmo tempo, caminho para inúmeras especulações e ajudando a compreender os projetos desses empreendimentos.

Trata-se, portanto, de analisar diferentes aspectos levando em conta o que se refere à linguagem do material explorado, às aproximações e usos de representações que cada comunidade faz de seus textos. Esse exame cuidadoso, considerando as interferências, impossíveis de controlar, permite observar como a cada época os diferentes atores envolvidos em criações/debates/discussões selecionam e fazem uso de determinadas ideias, conceitos e concepções científicas, na realização de suas produções, que estão sublinhadas nos museus.

Segundo Van Praët (1996), pesquisador do Museu de História Natural de Paris, em um estudo sobre a transformação dos museus de história natural em França, evidenciou a estreita ligação da evolução da ciência com a apresentação das ciências nessas instituições. Para o autor a "evolução da ciência, de seus objetivos e métodos, parece assim ter determinado do século $\mathrm{XV}$ ao $\mathrm{XIX}$ a transformação dos museus científicos e a forma de suas exposições" (VAN PRAËT, 1996, p. 143). No entanto, ele sublinha que as ciências, ainda hoje, continuam influenciando os museus científicos, mas a combinação vai além da apresentação dos objetos de coleção, que representavam, no passado, as pesquisas científicas. Atualmente, por vezes as apresentações do museu, prescindem dos objetos de coleção e combinam cada vez mais, outros e muito diversos fatores socioculturais, onde estão incluídos o lazer, a profissionalização dos ofícios da exposição e da cultura, e as novas tecnologias de comunicação.

A leitura contextualizada no tempo e no espaço da produção dos textos ajuda a desenredar diferentes elementos contidos nos discursos: questões formuladas e soluções; opções de escolha e decisões; ideias predominantes ou não, argumentos rejeitados ou ignorados; níveis de aceitação, apropriação e contestação; além de diferentes atores e lugares e suas maiores ou menores atuações. Os historiadores Cardoso e Vainfas (1997) auxiliam na articulação e na leitura dos diferentes aspectos quando se contrapõem àqueles que negam a ausência de história fora do texto. Para esses autores

Pelo contrário, trata-se, antes, de relacionar texto e contexto: buscar os nexos entre as ideias contidas nos discursos, as formas pelas quais elas se exprimem e o conjunto de determinação extratextuais que presidem a produção, a circulação e o consumo dos discursos. Em uma palavra, o historiador deve sempre, sem negligenciar a forma do discurso, relacioná-lo ao social (CARDOSO;VAINFAS, 1997, p. 378).

A escolha por uma análise contextualizada justifica-se na medida em que o texto é produto de intencionalidades. Entre sua produção e recepção existe um emaranhado de tempos, contextos e intenções, introduzidos pelo autor e pelo leitor nas suas respectivas ações de escrever e de ler.A consciência dessa construção favorece o distanciamento no momento da interpretação. Portanto, é a intenção do texto interagindo com a intenção do leitor que vai definir as margens de interpretabilidade. $O$ importante é saber ao que se visa com as intenções e estar atento para elas ao interpretar.

A observação do historiador da ciência Pestre (1996, p. I3) sobre o entendimento dos enunciados científicos vale como uma aproximação para o exercício da interpretação sobre a história de um museu. Para o autor, a ciência é um dispositivo que produz uma ordem e não um dispositivo que 'desvela' a ordem; nesse sentido, seria equivocado querer 'descontextualizar' seus enunciados, uma 
vez que estes são definidos no interior de uma determinada ordem capaz de se impor socialmente. Os enunciados não são independentes, com existência própria, eles estarão sempre vinculados àqueles que os detêm, seja o produtor ou o que dele se apropria. Usando ainda a produção ou posse dos enunciados científicos, o autor acrescenta que todo fechamento de um debate ou todo consenso é 'local' por natureza e é apenas compreendido no contexto preciso de sua elaboração. A lógica de um argumento redefine permanentemente a dinâmica dos demais (PESTRE, 1996, p. 20). Por outro lado, como mencionado anteriormente, no campo do intérprete do texto, ocorre o mesmo processo de localidade no tempo e no espaço. Nesse sentido, compreende-se que a interpretação do conteúdo do texto documental, escrito ou falado, vem de um lugar e de um tempo moldados por uma intenção, que se associam às perguntas (quando?; onde?; quem?; como?; para que?; o que? e por que?) que lhe são feitas e às respostas relativas às fontes, usadas para o desenvolvimento de um estudo.

$\mathrm{Na}$ abordagem contextualizada cabe considerar a importância de um movimento mais amplo relacionado à circulação das ideias de um lugar para outro. Aspecto ressaltado por Lopes (2004) ao se referir à forma de abordar as propostas de investigação:

[...] os intercâmbios mantidos pelas instituições museológicas latino-americanas do século XIX, foram aspectos constitutivos do próprio processo de consolidação da cultura científica no Brasil como a ampliação do alcance de tais exposições (Exposições Universais) através de seus relatos nos periódicos científicos e de divulgação da época (LOPES, 2004, p. 3).

A aproximação com essa visão orienta as interpretações e deve ser destacada quando se explora os museus (HEIZER, 2005). A circulação de ideias é um fator constitutivo da construção dos museus de ciências. Essa instituição de origem ocidental foi disseminada pelo mundo de tal maneira que pode ser encontrada nos lugares mais inusitados. Sem negligenciar a forma de apropriação de cada cultura, até hoje as unidades recém-criadas em geral se inspiram, em princípio, nos modelos originalmente europeus e norte-americanos.

Os estudos sociais da cultura científica oferecem uma base promissora de investigação. Se focalizada na instituição museu e, particularmente no museu de ciências e tecnologia, este se torna um universo a ser descoberto. Nessa perspectiva, o conhecimento sobre a instituição traz uma contribuição importante ao entendimento do seu papel na produção científica, na difusão do saber, assim como na preservação de objetos e na promoção de práticas sociais que procuram aproximar o leigo de um mundo considerado distante do seu cotidiano e entender o fenômeno complexo da apropriação social dessa instituição.

\section{Sublinhando o ponto de vista da história da ciência sobre a museologia}

Guardadas as devidas ressalvas, mesmo percebendo que o desenvolvimento do setor da ciência e a constituição de museus tenham se dado em grande medida por fortes ligações entre eles, são recentes as pesquisas que se preocupam em investigar os meandros dessa ligação sob um olhar crítico da história da ciência ${ }^{7}$. Os trabalhos realizados a partir de um viés da história social e cultural, e do ponto de vista dos estudos de museus (museums studies) são pouco frequentes, deixando um amplo campo a ser explorado no Brasil e mesmo no exterior ${ }^{8}$.

7 Alguns artigos com esse caráter podem ser encontrados na publicação Anais do Museu Histórico Nacional, v. 29, 1997. Edição comemorativa dos 75 anos da fundação do Museu Histórico Nacional. Entre eles o de Munteal Filho (1997), Kury e Camenietzki (1997). Um estudo exemplar é o de Lopes (1997).

8 Uma reflexão sobre o assunto ver Lopes e Valente (2009). 
A evidência da ampliação dessa possibilidade tem ficado mais explícita a partir de produções localizadas na última década e em recentes artigos ${ }^{9}$, que chamam atenção para o fato. Bennett, em um desses trabalhos, destaca dois importantes impulsos na articulação museu de ciências e história da ciência.

Primeiro, ela (a articulação) procura situar o recente interesse dos historiadores da ciência nos museus com um estudo mais amplo sobre museus em geral e aponta para o valor do amplo contexto para localizar a prática científica. Segundo, lembra aos historiadores da ciência que os museus não são somente objetos de estudo, mas também recursos vivos para a comunicação pública [...] (BENNETT, 2005, p. 602).

Segundo o mesmo autor, a história dos museus e de suas coleções pode ser uma importante fonte de pesquisa. Além disso, Bennett (2005) acrescenta que uma iniciativa propulsora desse movimento já havia sido manifestada com a criação da publicação Journal of the History of Collections, fruto do empenho de Arthur MacGregor, lançada em 1985. Admite nesse sentido, a criação de uma área de interseção entre história da ciência e museologia.Anunciando essa orientação deve-se acrescentar o lançamento em 2008 do primeiro número do periódico Museum History Journal ${ }^{10}$, com saída de dois volumes por ano. A publicação conta com importantes pesquisadores da história da ciência entre os membros do seu comitê editorial e foi dedicada à difusão de análises críticas relativas à história de museus.

A área assim se consolida, abrangendo diferentes formas institucionais e atividades museológicas. Entre elas podem ser citados: o museu do lluminismo, classificatório, de pretensões enciclopedistas do século XVIII; os museus formados pela herança das grandes exposições universais que seguiram os moldes da era tecnológica, dos projetos nacionalistas e os museus de natureza popular e de forte cunho educacional. Como diz Bennett, os museus de ciências do século passado possuíam uma característica marcante, por seu turno, segundo o autor: "As instituições do século XX mantiveram uma agenda educacional, entretanto com um perfil mais forte para a ciência e com maior especialização: como havia museus de ciência, e até mesmo da história da ciência.” (BENNETT, 2005, p. 604) Os museus registram e preservam coisas e concepções, mas também são poderosos instrumentos para traçar atitudes com relação à arte, à história e à ciência.

No museu, as ações de coletar e colecionar imprimem um significado à ciência ali produzida. Suas intenções promovem uma ordem para as coisas do mundo. Este lugar será um espaço privilegiado, em que os historiadores podem ter acesso e situar as práticas científicas:"Os museus refletem a ordem intelectual e social do seu tempo, sobretudo novos museus, uma vez que não foram feitos em vão, mas concebidos, estruturados e organizados como novos" (BENNETT, 2005, p. 603).

Ao enfrentar o desafio de análise dos museus pela perspectiva da história da ciência cumpre acrescentar o que Pestre (1996) em seu artigo, Por uma Nova História Social e Cultural das Ciências: novas definições, novos objetos, novas abordagens, procura, analogamente ao movimento da disciplina da história mais ampla, propor sobre novas possibilidades de investigação pelo viés da história da ciência.

Meu desejo é o de fazer aparecer, por de trás da aparência de trivialidade ou de não pertinência, aqueles objetos escondidos que, no entanto, são essenciais para uma boa compreensão das práticas científicas, obje-

9 A publicação ISIS, v. 96, de 2005 dedicou em sua seção "FOCUS" cinco artigos sobre a abordagem dos Museus pela ótica da História da Ciência.

100 periódico Museum History Journal é editado pela LeftCoast Press. Disponível em: <http://www. Icoastpress.com>. 
tos dotados de uma historicidade que permite fortemente à disciplina não ficar fechada em si mesma e se ligar à História cultural, à História industrial ou à dos instrumentos, em suma, objetos que permitem à história das ciências reintegrar o conjunto dos questionamentos históricos, sem nenhuma exceção (PESTRE, 1996, p. 23).

quadro estimulador de um novo olhar, sobre o que procurar e como procurar deriva de um momento de renovação que já conta, aproximadamente, com pouco mais de 40 anos, caracterizado pela prática da investigação interdisciplinar e que contempla abordagens problematizadoras, visando a redefinir a natureza das práticas científicas. É bom lembrar que os novos estudos sobre a natureza das práticas científicas ocorriam ao mesmo tempo em que eram travadas discussões em outros campos com interesses comuns aos da História da ciência, como a divulgação científica e a mediação sociocultural, debatida pelos movimentos do Public Understanding of Science e Science Literacy ", onde o museu e centros de ciências e a educação em ciências estavam imersos. Somam-se a estes setores, aqueles que no campo acadêmico se voltam para o pensamento sobre a ação dos museus, ou seja, a museologia e os estudos de museus (Museums Studies) ${ }^{12}$.

Sendo assim, não podem ser negligenciadas as mudanças que se processam, na área há pelo menos quatro décadas, nas instituições encorajadas a se adequarem a uma perspectiva de caráter social ${ }^{13}$. Nessa construção é importante incursionar pela disciplina que aborda a relação do sujeito com aquilo que é musealizado, a museologia. Área de conhecimento que, em torno de seu campo de ação, fornece elementos para a configuração do objeto de estudo, o museu de ciências e tecnologia. Nesse âmbito, as publicações provenientes de diferentes áreas disciplinares e que analisam os museus vêm fortalecer o setor ${ }^{14}$. À medida que as instituições ganham em importância, tende a crescer em quantidade e qualidade o investimento acadêmico sobre suas investigações.Ao mesmo tempo a afirmação da museologia observa de perto sua característica multidisciplinar, abrindo-se cada vez mais para interagir com diferentes saberes. Dessa forma, sua dimensão histórica vem contribuir para sua base teórica.

\section{Algumas considerações}

A identidade museológica vem, há algum tempo, valorizando-se com um consistente conjunto de definições e um corpo teórico que tem sido consolidado por meio de antologias ${ }^{15}$ e outras publicações ${ }^{16}$, algumas ainda dispersas, mas

II Alfabetização científica é uma expressão usada para designar o que o público em geral deve saber a respeito da ciência. Segundo Durant (2005) o termo deve ser olhado a partir da distinção entre três abordagens: conhecimento científico com ênfase no conteúdo, ênfase nos processos da produção do conhecimento científico e, por fim, a ênfase nas estruturas sociais ou nas instituições da ciência (cultura científica).

12 Uma fonte de informação é o site do departamento de Museum Studies da University of Leicester: $<$ http://www.le.ac.uk/ms/>.

13 Para aprofundar essa perspectiva problematizada da museologia em uma abordagem histórica, ver: Teather (1991); Gob e Drouguet (2003); Kaplan (1992). Ver também o periódico Museum and Society Disponível em:<http://www2.le.ac.uk/departments/museumstudies/museumsociety>.

I4 Periódicos recentemente editados, no Brasil, têm contribuído para a disseminação em âmbito nacional, o conhecimento sobre a museologia, o que até pouco tempo era feito exclusivamente por periódicos estrangeiros: Revista Museologia e Patrimônio: <http://revistamuseologiaepatrimonio.mast.br/index.php/ ppgpmus/>e a Revista Museologia \& Interdisciplinaridade: <http://seer.bce.unb.br/index.php/museologia/ issue/current/showToc>.

15 Entre outras, três antologias mostram a preocupação em organizar o campo da Museologia: Desvallées, Bary e Wasserman (1992; 1994); Vergo (1989).

16 Publicação que trata de pontos de vista de diferentes pesquisadores, sobre a definição de museu ver: Mairesse e Desvallés (2007). 
que têm servido de fundamentação básica para a reflexão no campo, em que pesquisadores brasileiros também têm se expressado. No Brasil, a museologia conta com um comitê no CNPq o que configura um espaço importante de expansão.

Neste caminho os museus podem ser vistos como um novo objeto de desafio. Historiadores da ciência ${ }^{17}$, como Lopes (2005), Alberti (2005), Forgan (2005), Kohlstedt (2005) e Heizer (2006), parecem convergir para a mesma ideia e oferecem em seus trabalhos diversos aspectos de reflexão sobre a instituição museológica, da pesquisa à preservação, da educação à comunicação, permitindo dar a esta área de conhecimento outros contornos.

A construção e a idealização dos espaços museológicos, no parecer de Forgan (2005), são fontes de observação que podem indicar o lugar da ciência no tempo e no espaço, envolvendo competições entre conhecimento e reivindicações institucionais, muitas vezes distanciando as propostas iniciais de eficiência ou eficácia do museu.

A construção de um novo museu é uma tarefa prestigiosa, oferecendo aos arquitetos a oportunidade de criar sua marca no panorama internacional. Porém, o nível com que arquitetos, ou certamente seus clientes, levam em consideração as coleções que seus designers pretendem abrigar fornece indícios sobre o distanciamento entre o discurso arquitetônico e a compreensão da ciência, assim como as relações pessoais em cada caso (FORGAN, 2005, p. 576).

É possível afirmar que há um consenso de que os museus de ciências e tecnologia também são vistos como lugares de status e de respeito ${ }^{18}$. A forma como são erigidos provoca indagações de diferentes ordens, por exemplo: do conhecimento a ser produzido, das pretensões públicas da instituição no que tange a sua repercussão cultural e recepção de audiências. $O$ questionamento da complexidade desse espaço pode levar a compreender melhor como a ciência se reposiciona no tempo em relação à economia, à cultura e aos espaços de produção intelectual e de difusão (BRUNO, 2007).

São muitas as questões que permitem revitalizar o interesse na história dos museus. Seguindo Kohlstedt (2005, p. 587), um exemplo está no esforço de identificação dos caminhos nos quais as aspirações científicas e atividades desenvolvidas, nestes lugares, seriam estruturadas por suas circunstâncias específicas.A ação sugerida viria contribuir para o deslocamento da análise das instituições, por uma única via, para uma visão em que os pesquisadores se detivessem mais no patrimônio de diferentes ideais. Nesse sentido, a sugestão se refere à mudança de um modo restrito à realização de funções comuns (pesquisa científica, conservação e documentação de coleções, dentre outras) e a apresentação de informações limitadas a servir como pano de fundo nas Histórias biográficas e intelectuais. Para um modo de análise voltado para as considerações sobre a cultura e sobre o saber científico de uma época e menos voltado para os aspectos factuais dessas instituições.

Outros olhares sobre diferentes objetos de investigação jogam luz sobre o que parece invisível. Os novos estudos conduzem à reconsideração dos projetos das instituições e da prática de suas atividades em relação às circunstâncias políticas, econômicas e sociais, que promovem mudanças institucionais relativas à suas funções, perfil e missão. São os programas de políticas públicas e as intrincadas

17 Ver o periódico, da ISIS, n. 96, 2005 - seção FOCUS.

18 Um dos resultados da pesquisa realizada em 2000 no Museu de Astronomia e Ciências Afins evidenciou este fato (GOUVÊA et al., 2002). 
relações com organismos internacionais que orientam perspectivas diferentes para as instituições. Nessa abordagem, observa-se que no plano das políticas públicas é evidente a necessidade de se estabelecer um novo olhar sobre o patrimônio cultural da ciência e tecnologia brasileiro cujos valores histórico, cultural, científico e tecnológico serão mais amplamente reconhecidos na medida de um maior interrelacionamento entre órgãos das áreas da Cultura e da Ciência e Tecnologia (GRANATO; OLIVEIRA, 20 I2;VALENTE; HANDFAS, 20I2).

Nesse sentido, a temática da exclusividade da missão da pesquisa científica dos museus desdobra-se para a dimensão mais ampla da educação e comunicação, cuja atenção se volta para o público, em sociedades supostamente mais democráticas. É o 'museu em movimento' que, ao se adaptar ao mundo, em tempos diferentes, carrega com ele ou se desfaz de elementos do passado em uma dinâmica de constante tensão, realizando um caminho de continuidades e descontinuidades. Exemplos desse fenômeno são os estudos sobre os museus universitários, científicos por excelência, que se veem pressionados a se aproximar do público a fim de garantirem sua existência ${ }^{19}$.

Os últimos 20 anos testemunham uma ebulição na produção de pesquisas relacionadas à instituição museu. No Brasil um número considerável de trabalhos está dirigido para a compreensão dos processos comunicacionais em museus e suas implicações para os estudos de público em geral e específicos - voltados para questões de marketing, de educação e de comunicação (ALMEIDA, 20I2; CARVALHO, 2005; CAZELLI, 2005; 20I2; COIMBRA, 20I2; CURY, 2005; FALCÃO, 2006; KÖPTCKE, 20 I2; LOPES, 2009; MARANDINO, 200 I; MASSARANI, 2008;VALENTE, 2007; SEIBEL, 2008, entre outros). Outros estão relacionados às mudanças conceituais e museográficas dos processos expositivos de museus de ciência, e áreas disciplinares específicas.Além desses, a temática dirigida especialmente para os museus de ciência e suas coleções tem interessado um número expressivo de pesquisadores que ingressam nos programas de pós-graduação ${ }^{20}$.

Esta última temática, segundo Lopes (2004), aproxima-se do contexto dos processos de democratização do país que levaram o CNPq a adotar políticas mais contundentes de apoio a museus de ciência e a institucionalização de disciplinas como a História da Ciência e Divulgação da Ciência. Esta última disciplina conta com um comitê assessor no CNPq, implantado em 2004, ato que veio valorizar o setor então discriminado pelos próprios pesquisadores que realizam divulgação científica. Essa mudança de comportamento foi objeto de estudo confirmando a ascendência do setor.A dissertação de Navas (2008) analisa esse comitê e da forma como vem sendo tratada a área da divulgação científica no Brasil comparado com outros países da América Latina, onde o museu aparece como equipamento cultural de destaque.

Por fim, vale lembrar que se tem sublinhado, ainda, em diferentes encontros de contornos mais interdisciplinares, que os museus de ciência e tecnologia, são instituições promotoras da cultura cientifica e se pautam mais pelo objetivo de educar, no sentido de imprimir um espírito cientifico nos indivíduos, do que o de ensinar leis e fundamentos científicos. Compreensão que evidencia diferentes tendências, tanto no que diz respeito à atuação de aproximação dos museus com os diferentes públicos, quanto na produção de pesquisas em âmbito acadêmico.

19 Pesquisas particularmente relacionadas aos museus universitários, ver em Almeida (200I); Lopes e Figueirôa (2003); Lourenço (2005).

20 Ver dissertações defendidas em: Programa de pós-graduação Patrimonio e Museologia - UNIRIO/ MAST. Disponível em: http://www.unirio.br/cch/ppg-pmus/ ; e o Grupo de Estudo e Pesquisa em Educação Não Formal e Divulgação em Ciência - GEENF <http://www.geenf.fe.usp.br/divulga.php>. 
Para responder as exigências da democracia moderna, Stengers (1997) afirma que os futuros cidadãos deverão ser capazes de se interessar pela ciência, 'tal como ela se faz', com suas relações de força, suas incertezas, suas múltiplas constatações que suscitam suas pretensões, as alianças entre interesses e poderes que a orientam, que hierarquizam suas questões, desqualificando umas e privilegiando outras.

Tornar acessível ao público, e na perspectiva da inclusão social, a cultura cientifica técnica e industrial, os avanços que se produzem nas ciências fundamentais, nas suas aplicações tecnológicas, nas suas alternativas industriais, assim como as mudanças sociais que elas induzem, é o que se busca. Mas, o vasto domínio da Cultura Cientifica Técnica e Industrial, que vai da transmissão de conhecimento científico de base aos processos de mediação, para melhor fazer compreender ao público os andamentos e as relações sociais ligadas às mudanças econômicas e ecológicas, necessita também da parte dos mediadores do museu uma melhor e mutua compreensão entre esses atores tão diferentes.

Com essa preocupação, cabe assinalar que os estudos desenvolvidos guardam um estreito interesse sobre os frequentadores da instituição (CAZELLI; COIMBRA, 2012) e vêm redimensionar o caráter público não só do espaço museológico, mas também da relação dos indivíduos com a ciência. Todos os processos de aproximação do público com a ciência são construções históricas, implementadas simultaneamente à promoção das ciências ao longo dos séculos, e em grande medida no interior dos museus, também, envolvidos nessa promoção.

Os estudos produzidos e aqui assinalados tratam de alguma forma da construção da categoria de museu de ciência e tecnologia. Esses estudos fornecem subsídios para entender a formação desse tipo de museu no país e oferecem pistas para a identificação e compreensão das permanências tradicionais na concepção das atuais iniciativas institucionais. As pesquisas vêm assim sinalizando um caminho a ser seguido.

São estes estudos que contribuem para o fortalecimento do campo disciplinar da museologia, acrescentando modos de ver e de se relacionar com o museu. Nesse caminho, deve-se destacar a pesquisa, fundamentada na perspectiva da história da ciência, de Lopes (1997) sobre o Museu Nacional do Rio de Janeiro, que veio impulsionar a vertente da história da museologia no Brasil. Sua contribuição tem ampliado essa vertente, abrindo uma linha de pesquisa importante na construção da trajetória da museologia brasileira. A exploração da instituição museológica por essa via descortina uma feição até então escondida do museu. No caso brasileiro, além de qualificar a ciência produzida no país ainda no século XIX, valoriza o campo da museologia com a introdução de instrumentos de pesquisa que enriquecem futuras análises.

Os aspectos abordados no decorrer do artigo sugerem levantar a questão que se refere ao lugar em que se situa o museu de ciência e tecnologia na produção da museologia e do patrimônio de ciência e tecnologia e ou no cenário mais amplo da museologia e do patrimônio.

Os estudos voltados para os museus de ciências e tecnologia, empreendidos na perspectiva anunciada, terão como áreas de intersecção a história da ciência e a museologia. Os museus comportam mudanças para se adequar a um novo momento. Toda adaptação implica a perda ou recuperação de status, no que diz respeito, por exemplo, ao público geral, aos pesquisadores, aos museólogos e a outros profissionais, as coleções, as disciplinas e as apresentações. A acomodação exige um constante movimento de atualização. Mais do que nunca, os museus de ciências, como instituições renovadas, são considerados espaços 
privilegiados de divulgação científica e de preservação do patrimônio da ciência e tecnologia. Nesse sentido, o estreitamento dessas instituições com as ações de desenvolvimento científico tecnológico só tende a fortalecer os dois setores.

A ideia de promover a cultura científica na sociedade esteve presente na grande maioria dessas instituições, em lugares e épocas diferentes, a partir de perspectivas que guardam características de seu tempo e de seu contexto. De qualquer forma podem-se destacar marcos que permitem constituir tendências ao logo do tempo.

A história dos museus de ciências e tecnologia no Brasil é recente, assim como a produção de pesquisas relativas à museus, impulsionadas no país a partir das últimas décadas ${ }^{21}$. Nesse sentido, a análise sugerida por uma abordagem historicamente contextualizada poderá contribuir no enfrentamento dos desafios dos museus atuais e contribuir para a produção no campo da história da ciência e da museologia.

\section{Referências}

ALBERTI, Samuel J. M. M. Objects and the museum. ISIS, n. 96, p. 559-57I, 2005. ALMEIDA,Adriana Mortara.A observação de visitantes em museus: sobre ratos e seres humanos. Revista Museologia \& Interdisciplinaridade, v. I, n. 2, p. I0-29, 2012. ALMEIDA, Adriana Mortara. Museus e coleções universitárias: por que museus de arte na Universidade de São Paulo? 200I. Tese (Doutorado)- Escola de Comunicação, USP, São Paulo, $200 \mathrm{I}$.

ARAGÃO, Thayse Zambon Barbosa. Concepções de ciência presentes na divulgação e prática de instituições não formais de ensino de ciências. 2013. Dissertação (Mestrado)- Programa de Pós-Graduação Multiunidades em Ensino de Ciências e Matemática, Universidade Estadual de Campinas, Campinas, 2013. BENNETT, Jim. Museums and the history of Science. ISIS, v. 96, n. 4, p. 602-608, 2005. BENNETT,Tony.The birth of the museum: history, theory, politics. London:Routledge, 1996. BERGERON,Yves; DAVALLON, Jean. Recherche. In: DESVALEES, D'André; MAIRESSE; François (Org.). Dictionaire encyclopédique de muséologie. Paris: Armand Colin, 20I I. p. 527-542.

BRUNO, Maria Cristina de Oliveira. Museus, ciência, tecnologia e sociedade: um desafio de gerações. In:VALENTE, Maria Esther Alvarez (Org.). Museus de ciência e tecnologia: interpretações e ações dirigidas ao público. Rio de Janeiro: MAST, 2007. p. 4 I-46.

CARDOSO, Ciro Flamarion Santana;VAINFAS, Ronaldo. Domínios da história. Rio de Janeiro: Campus, 1997.

CARVALHO, Rosane. A transformação da relação museu e público: a influência das tecnologias da informação e comunicação no desenvolvimento de um público virtual. 2005. Tese (Doutorado)- Escola de Comunicação, Universidade Federal do Rio de Janeiro (UFRJ) [em convênio com] IBICT, Rio de Janeiro, 2005.

CAZELLI, Sibele et al. Mediação ciência e sociedade: o caso do museu de astronomia e ciências afins. In: MASSARANI, Luisa;ALMEIDA, Carla (Ed.).Workshop sul-americano \& escola de mediação em museus e centros de ciência. Rio de Janeiro: FIOCRUZ, 2008. p. 6 I- 68.

CAZELLI, Sibele.Alfabetização científica e os museus interativos de ciência. Dis-

21 O estudo realizado por Cury (2005) registra um importante levantamento das pesquisas acadêmicas em museus brasileiros. 
sertação (Mestrado)- Departamento de Educação, Pontifícia Universidade Católica, Rio de Janeiro, 1992.

CAZELLI, Sibele. Ciência, cultura, museus, jovens e escolas: quais as relações? 2005. Tese (Doutorado)- Departamento de Educação, Pontifícia Universidade Católica, Rio de Janeiro, 2005.

CAZELLI,Sibele; COIMBRA, Carlos Alberto Quadros. Pesquisas educacionais em museus: desafios colocados por diferentes audiências. In:WORKSHOP INTERNACIONAL DE PESQUISA EM EDUCAÇÃO EM MUSEUS, I., 20 I2, São Paulo. Anais... São Paulo: Faculdade de Educação da USP, 20I2. Disponível em:<http:// www.geenf.fe.usp.br/v2/wp-content/uploads/20I3/0I/Mesa I_Cazelli-protegido. pdf>.Acesso em: I5 jan. 2014.

COIMBRA, Carlos et al.Tipos de audiência segundo a autonomia sociocultural e sua utilidade em programas de divulgação. Revista Tempo Brasileiro, n. I88, p. II3-I 24, jan./mar. 2012.

CURY, Marília Xavier. Comunicação museológica: uma perspectiva teórica e metodológica de recepção. 2005. Tese (Doutorado)- Escola de Comunicações e Artes da Universidade de São Paulo, 2005.

DESVALLÉES, A. Présentation. In: BARY, Marie-Odile de et al. (Org.).Vagues: une anthologie de la nouvelle museéologie. France: Éditions W, M.N.E.S, I 992. (Collection museologia).v. I. p. 15 -39.

DESVALLÉES, A; BARY, Marie Odile de;WASSERMAN, Francoise (Org.).Vagues: une antologie de la nouvell museologie. Paris: Éditions W, M.N.E.S., 1992. (Collection museologie). v. I.

DESVALLÉES, A; BARY, Marie Odile de;WASSERMAN, Francoise (Org.).Vagues: une antologie de la nouvell museologie. Paris: Éditions W, M.N.E.S., 1994. (Collection museologie).v. 2.

DURANT, John. O que é alfabetismoo cienífco? In: MASSARANI, Luisa;TURNEY, Jon; MOREIRA, Ildeu de Castro (Org.). Terra Incógnita: a interface entre ciência e público. Rio de Janeiro:Vieira \& Lent, 2005. (Série terra incógnita). p. 13-26.

FALCÃO, Douglas. A study of visitors' understanding of interactive exhibits in science museums by means of stimulated recall method. 2006. Thesis (PhD)- Institute of Education, University of Reading, UK, 2006.

FOCUS. ISIS, v. 96, 2005.

FORGAN, Sophie. Building the museum. ISIS, v. 96, p. 572-585, 2005.

GOB, André; DROUGUET, Noémie (Org.). La muséologie: histoire, développements, enjeux actuels. Paris: Ed. Armand Colin, 2003.

GOUVÊA, Guaracira et al. A study of the process of museographic transformation in two exhibitions at MAST. In: EVALUATION: multi-purpose applied research. Quebec: Ed. MultiMondes, 2002. p. 108-124.

GRANATO, Marcus; OLIVEIRA, Pedro L. C. de.A institucionalização do patrimônio cultural da ciência e tecnologia. In. OLIVEIRA, Lucia Maria V. de; SILVA, Maria Celina, S. de M. e. (Org.). Políticas de aquisição e preservação de acervos em universidades e instituições de pesquisa. Rio de Janeiro: Museu de Astronomia e Ciências Afins/MAST, 2012. p. 317-342.

HANDFAS, Ethel R. Políticas públicas de C\&T e museus de ciência: o Museu de Astronomia e Ciências Afins. 2013. Dissertação (Mestrado)- Programa de Pós-Graduação em Museologia e Patrimônio, Universidade Federal do Estado do Rio de Janeiro, Rio de Janeiro, 2013. 
HEIZER,Alda. Museus de ciências e tecnologia: lugares de cultura? Revista SBHC, v. 4, n. I, p. 56-6I, jan. /jun. 2006.

HEIZER,Alda. Observar o céu e medir a terra: instrumentos científicos e a participação do Império do Brasil na exposição de Paris de 1889. 2005. Tese (Doutorado)- Instituto de Geociências, Universidade Estadual de Campinas, Campinas, 2005. HEIZER, Alda; VIDEIRA, Antonio Augusto Passos (Org.). Ciência e civilização e império nos trópicos. Rio de Janeiro:Acess, 2001.

JACOMY, Bruno. Instrumentos, máquinas e aparatos interativos de ciência e tecnologia exibidos nos museus. In:VALENTE, Maria Esther Alvarez (Org.). Museus de ciência e tecnologia: interpretações e ações dirigidas ao público. Rio de Janeiro: MAST, 2007. p. I5-28.

KAPLAN, Flora. Growing pains: it is science? it is art? it is necessary? the discipline of museum studies is growing up, and beginning to assert its rights. Museum News, jan./feb. 1992.

KOHLSTEDT, Sally Gregory. Thoughts in things: modernity, history, and north american museums. ISIS , n. 96, p. 586-60I, 2005.

KÖPTCKE, Luciana Sepúlveda. Público, $\circ X$ da questão? a construção de uma agenda de pesquisa sobre os estudos de público no Brasil. Museologia e Interdisciplinaridade, v. I, n. I, p.209-235, jan./jul. 2012.

KURY, Lorelai Brilhante; CAMENIETZKI, Carlos Ziller. Ordem e natureza: coleções e cultura científica na Europa Moderna. Anais do Museu Histórico Nacional, v. 29, p. 57-86, 1997.

LOPES, Maria Margaret. A favor da descolarização dos museus. Educação e Sociedade, n. 40, p. 443-445, dez. 1991.

LOPES, Maria Margaret.A mesma fé e o mesmo empenho em suas missões científicas e civilizadoras: os museus brasileiros e argentinos do século XIX. Revista Brasileira de História, v. 2 I, n. 4 I, p. 55-76, 200 I.

LOPES, Maria Margaret. Aproximando os museus das relações de gênero na história: Bertha Lutz e o papel educativo dos museus. Revista Musas, maio 2006a.

LOPES, Maria Margaret. Brazilian museums of natural history and international exchanges in the transition to the 20th century. In: PETITJEAN, P. et al. Science and empire. Dordrecht: Kluwer Academic Press, 1992. p. 193-200.

LOPES, Maria Margaret. Latin american museums: cooperative studies and links. In: INTERNATIONAL CONGRES OF HISTORY OF SCIENCE: Scientific Instruments and Museums, 20.,Turnhout, 2002. Proceedings... Brepols Publishers, 2002. v. 16, p. $221-236$.

LOPES, Maria Margaret. Le rôle des musées, de la science, et du public au Brésil. In:WAAST, Roland (Dir.). Les sciences hors d'occident au XXe siècle. Paris: Orstom, 1996.

LOPES, Maria Margaret. Museu perspectiva de educação em geologia. 1988. Dissertação (Mestrado)- Faculdade de Educação, Universidade Estadual de Campinas, Campinas, 1988.

LOPES, Maria Margaret. Museus e educação na América Latina: o modelo parisiense e os vínculos com as universidades. In: GOUVÊA, G. et al. (Org.). Educação e museu: a construção social do caráter educativo dos museus de ciências. Rio de Janeiro: FAPERJ, 2003b. p. 63-82.

LOPES, Maria Margaret. O Brasil descobre a pesquisa científica: os museus e as ciências naturais no século XIX. São Paulo: Hucitec, 1997. 
LOPES, Maria Margaret. Por que história nos museus e centros de ciência. (comunicação). In: CONGRESSO MUNDIAL DE CENTROS DE CIÊNCIA, 4., 2005, Rio de Janeiro. Anais... Rio de Janeiro: [s.n.], 2005.

LOPES, Maria Margaret. Por que história nos museus e centros de ciências? In: MARANDINO, Martha;ALMEIDA. Adriana Mortara;VALENTE, Maria Esther. Museu: lugar do público. Rio de Janeiro: Ed. Fiocruz, 2009.

LOPES, Maria Margaret. Programa de Pós-Graduação em ensino e história da ciência da terra: projetos de pesquisa sob supervisão de M. M. Lopes. In: CADERNO de resumos das Pesquisas (IG-DGAE - Pós-Graduação - EHCT). Campinas, 2004. p. 4-I4.

LOPES, Maria Margaret. Trajetórias museológicas: moluscos no Museu Paulista e feminismos no Museu Nacional (a museologia histórica e sua contribuição à análise da cultura científica no Brasil: 2. parte). In: RELATÓRIO do projeto de pesquisa - CNPq. Campinas: UNICAMP, Instituto de Geociências, 2006b.

LOPES, Maria Margaret; FIGUEIRÔA, Silvia F. de M.A criação do Museu Paulista na correspondência de Hermann von lhering (I850-1930). Anais do Museu Paulista: História e Cultura Material, nova série, v. I0/I I, p. 23-35, 2002-2003.

LOPES, Maria Margaret; MURRIELLO, Sandra Elena. Ciências e educação em museus no final do século XIX. História, Ciências, Saúde, v. I2, supl., p. I3-30, 2005.

LOPES, Maria Margaret; PODGORNY, Irina. The shaping of latin american museums of natural history, I850-1890. Osíris, v. I5, p. 108-18, 2000.

LOPES, Maria Margaret;VALENTE, Maria Esther. Negotiations of meanings, audiences and apparatuses in the Museums and Science Centres of the 2 Ist century. In: CIMUSET CONFERENCE. Proceedings... Serbia, Belgrado: [s.n.], 2009.

LOURENÇO, Marta C. Between two worlds: the distinct nature and contemporary significance of university museums and collections in Europe. 2005. Dissertação (Doutorado)- Conservatoire National des Arts et Métiers, Paris, 2005. LOURENÇO, Marta C.; GESSNER, Samuel. Documenting collections: cornerstones for more history of science in museums. Science \& Education, Dec. 2012. MAIRESSE, François; DESVALLÉES, André. Brèves histoire de la muséologie, des inscriptions au musee virtuel. In: MARIAUX, Pierre Alain (Org.). L'objet de la muséologie. Neuchâtel: Institut d'Histoire et d'art et de Muséologie, Université de Neuchâtel, 2005. (La collection l'atelier de thesis). p. I-50.

MAIRESSE, François; DESVALLÉS,André. (Org.).Vers une redéfinition du musée? Paris: L'Harmattan, 2007.

MARANDINO, Martha. Conhecimento biológico nas exposições de museus de ciência: análise do processo de construção do discurso expositivo. 200I. Tese (Doutorado)- Faculdade de Educação, Universidade de São Paulo, São Paulo, $200 \mathrm{I}$. MASSARANI, Luisa; ALMEIDA, Carla (Ed.). Workshop sul-americano \& escola de mediação em museus e centros de ciência. Rio de Janeiro: FIOCRUZ, 2008. MUNTEAL FILHO, Oswaldo. Todo um mundo a reformar: intelectuais, cultura ilustrada e estabelecimentos científicos em Portugal e no Brasil, I779 -I808. Anais do Museu Histórico Nacional, v. 29, p. 87-108, 1997.

NAVAS, Ana Maria. Concepções de popularização da ciência e da tecnologia no discurso político: impactos nos museus de ciência. 2008. Dissertação (mestrado)- Faculdade de Educação, Universidade de São Paulo, São Paulo, 2008.

PESTRE, Dominique. Por uma nova história social e cultural das ciências: novas definições, novos objetos, novas abordagens. Cadernos IG/UNICAMP, v. 6, n. I, p. 3-56, 1996. SCHIELE, Bernard; KOSTER, Emly. La revolution de la museologie des sciences. 
Paris: Editions Multimondes, 1998.

SEIBEL, Maria llone. Abordagens pedagógicas e o papel dos setores educativos nos museus de ciência. 2008. Tese (Doutorado)- Programa de Pós-Graduação em Ensino e História de Ciências da Terra, UNICAMP, Campinas, 2008.

STENGERS, Isabelle. Sciences et pouvoirs. Paris: La Découverte, 1997.

TEATHER, J. Lynne. Museum studies: refleting on reflective practice. Museum Management and Curatorship, v. 10, p. 403-417, 1991.

VALENTE, Maria Esther Alvarez. (Org.). Museus de ciência e tecnologia: interpretações e ações dirigidas ao público. Rio de Janeiro: MAST, 2007.

VALENTE, Maria Esther Alvarez. Museus de ciências e tecnologia no Brasil: uma história da museologia entre as décadas de 1950-1970.2008.Tese (Doutorado)Programa de Pós-Graduação em Ensino e História de Ciências da Terra, IG/ UNICAMP, Campinas, 2009.

VALENTE, Maria Esther Alvarez; HANDFAS, Ethel R. O patrimônio cultural científico e tecnológico brasileiro e a importância de políticas públicas para sua preservação. Revista Ciencias Estratégicas, v. 20, n. 28, p. 27I- 284, jul./dic. 2012. VAN PRAËT, Michel. Cultures scientifiques et musées d'histoire naturelle em France. Hermés, n. 20, p. I43-148, 1996.

VERGO, Peter (Org.). The new museology. London: Reaktion Books Ltda, 1989.

\section{Sites Consultados}

Cursos de Museologia graduação e Pós graduação. Disponível em: <http://www. concursosmuseologia.com.br/p/onde-estudar.html>. Acesso em: 10 fev. 2014.

Grupo de Estudo e Pesquisa em Educação Não Formal e Divulgação em Ciência - GEENF.Disponível em: <http://www.geenf.fe.usp.br/divulga.php>.Acesso em: 10 fev. 2014. ICOM. Disponível em: <http://icom.museum/the-organisation/icom-in-brief/>. Acesso em: 10 fev. 2014.

Journal of the History of Collections. Disponível em: <http://www.history.ac.uk/ history-online/journal/journal-history-collections>. Acesso em: 10 fev. 2014.

Museum and Society. Disponível em: <http://www2.le.ac.uk/departments/museumstudies/museumsociety>.Acesso em: 10 fev. 2014.

Museum History Journal. Disponível em: <http://www.lcoastpress.com/journal. php?id=6>. Acesso em: 10 fev. 2014.

Museum Studies of University of Leicester: Disponível em: <http://www.le.ac. $\mathrm{uk} / \mathrm{ms} />$. Acesso em: $10 \mathrm{fev} .2014$.

Programa de Pós-graduação Patrimonio e Museologia - UNIRIO/MAST. Disponível em: <http://www.unirio.br/cch/ppg-pmus/>. Acesso em: 10 fev. 2014.

Revista Museologia \& Interdisciplinaridade. Disponível em: <http://seer.bce.unb. br/index.php/museologia/issue/current/showToc $>$. Acesso em: 10 fev. 2014.

Revista Museologia e Patrimônio. Disponível em: <http://revistamuseologiaepatrimonio.mast.br/index.php/ppgpmus/>.Acesso em: 10 fev. 2014.

Science\&Education.Disponível em:<http://link.springer.com/article/ I0.1007\%2Fs I I I9I0| 2-9568-z>.Acesso em: 10 fev. 2014. 